\title{
The ongoing development of mathematics teachers' knowledge and practice: considering possibilities, complexities, and measures of teacher learning
}

\author{
Gwendolyn M. Lloyd
}

Published online: 7 May 2013

(C) Springer Science+Business Media Dordrecht 2013

The professional learning of mathematics teachers is an area of central concern in the field of mathematics teacher education. Researchers in mathematics teacher education strive to understand changes in teachers' knowledge and practice over time and in different contexts. Much of the research in our field aims to document, understand, and measure the impact of opportunities for teachers to learn through diverse experiences ranging from coursework to practice-based professional learning communities. The three articles in this issue of the Journal of Mathematics Teacher Education (JMTE) contribute to this body of scholarship by reporting about important questions and issues emerging from professional development activities in three countries. Each article builds on previous work in mathematics teacher education in significant ways and, through the insights each provides, opens the door for further research about teacher learning.

Two of the articles in this issue provide analytic accounts of the possibilities and complexities of teachers' joint observation and discussion of practice. Alf Coles's reflection on a video-based discussion group and Takeshi Miyakawa and Carl Winsløw's account of an "open lesson" reveal the potential for teachers to learn together through the development of shared knowledge about mathematics teaching. This potential is striking when we consider that much of teachers' daily work occurs in the privacy of individual classrooms. It was beyond the scope of either of these studies to examine or measure changes in teachers' knowledge or practice; instead, the researchers focused on exploring what might be the educative aspects of teachers' practice-based discussions. Yet, it is natural to wonder about the impact of such professional development activities on the knowledge and practices of participating teachers. Yasemin Copur-Gencturk and Sarah Lubienski shift our focus to the measurement of the impact of coursework on teachers' mathematical knowledge. Through their examination of the types of changes that two commonly used instruments detected in teachers' mathematical knowledge during graduate courses, these authors provide some evidence for theoretical distinctions among certain components of teachers' mathematical knowledge.

G. M. Lloyd $(\bowtie)$

The Pennsylvania State University, University Park, PA, USA

e-mail: 1loyd@psu.edu 
In "Using video for professional development: the role of the discussion facilitator," Alf Coles analyzes his role as discussion facilitator for a group of secondary mathematics teachers participating in a video-based professional development group in the United Kingdom. Of particular interest to Coles was his role in the establishment of non-evaluative modes of discourse among the teachers as they watched and discussed videos from their classrooms. Whereas previous research has suggested that viewers of video tend to assume an evaluative stance at the outset of discussion, this article identifies deliberate efforts made by a facilitator to focus teachers' initial discussions on developing an account of the events in the video clip-reconstructing them rather than immediately evaluating or interpreting them.

Based on his reflections on his role as facilitator and guided by enactivist category theory, Coles offers suggestions, ripe for further study, about why a reconstruction phase followed by an interpretation phase may provide a productive structure for video discussions. He suggests that when teachers begin their discussion of a video clip with an evaluative stance, they are primarily using perspectives and practices with which they are already deeply familiar. As he writes, "By interpreting events at this level of generality, there is little scope for noticing anything that may allow an extension to such established patterns of noticing." In other words, opportunities for teachers to learn from video discussion seem to be limited when they jump quickly into evaluation. In contrast, when teachers' discussions begin with the development of descriptive accounts, the discourse is necessarily at the detail level. From that starting point, teachers gain opportunities to identify and discuss new aspects of instructional practice (with potential for further examination in their own classroom work) as they shift to more general descriptions of what they have seen on video.

Neither the distinction between reconstruction and interpretation nor the notion of multiphased video discussion is new in the literature, as Coles discusses. What this article contributes to mathematics teacher education is fresh insights into lesser known aspects of the facilitator's work. These include decision points such as how one might support teachers in getting into detailed discussion as they reconstruct a video's events, when a facilitator might decide to replay a video or initiate the transition from the reconstruction phase to the interpretation phase, and how and why the facilitator articulates issues teachers are discussing in the interpretation phase ("metacomments"). These decision points bring needed transparency to the facilitator's role by articulating the multiple efforts by Coles to shape opportunities for teacher learning during video analysis. His decision points offer useful tools for other discussion facilitators and possible areas of inquiry for other researchers.

The opportunity for teachers to learn together through observation and discussion of practice is also central to the article by Takeshi Miyakawa and Carl Winsløw, "Developing mathematics teacher knowledge: the paradidactic infrastructure of 'open lesson' in Japan." In contrast to many other parts of the world, where possibilities for participation in professional learning communities such as video groups and lesson study are available only to a minority of teachers, in Japan open lessons belong to teachers' ordinary experience. Miyakawa and Winsløw present a theoretical approach, based in anthropological theory of the didactic, to studying mathematics teachers' knowledge and its development in the open lesson format. The authors then use this theoretical approach to analyze data from one instantiation of an open lesson (e.g., the teacher's written lesson plan, video of the lesson taught to children, artifacts from the lesson, and video of the post-lesson discussion among the participating teachers) to identify and illustrate essential characteristics of the open lesson.

Miyakawa and Winsløw's analysis attends to aspects of the pre-didactic organization represented in the lesson plan, the didactic techniques observed in the teacher's lesson with 
children, and the post-didactic discussion among the teachers. A particularly noteworthy aspect of the post-didactic discussion is how the questions and comments of teachers seemed to deal little with specifics of the lesson or particular students, but rather with connecting practices observed in the lesson directly to theoretical principles. The postdidactic discussion "strictly focuses on the didactic techniques of the lesson, and their relations to explicit theoretical principles." What is illustrated by the analysis of the open lesson in this article is that, through discussion of practice, teachers can collaboratively develop and elaborate theoretical ideas around specific aspects of instructional practice. The authors suggest that Japanese dictionaries of mathematics teachers' terms offer evidence of the extent of this shared didactic theory. How this theory develops among teachers and how that shared development impacts mathematics teachers' classroom practices appear to be promising areas for future research.

In "Measuring mathematical knowledge for teaching: a longitudinal study using two measures," Yasemin Copur-Gencturk and Sarah Lubienski report about their measurement of the impact of two graduate courses, offered through a university as part of a professional development program in the United States, on teachers' mathematical knowledge. The researchers were interested in measuring the extent to which elementary and middle school teachers' specialized and common content knowledge changed during a hybrid content/ pedagogy course designed specifically for elementary teachers and a mathematics course focused on real-world applications (but not focused on mathematical knowledge specific to elementary school). Teachers completed the hybrid course during the fall of one academic year, followed by the mathematics course during the spring of the next academic year. To measure changes in teachers' knowledge, Copur-Gencturk and Lubienski used two different measures and compared how each measure detected changes in teachers' knowledge during the two courses. Whereas the Learning Mathematics for Teaching (LMT) instrument was designed to assess elementary teachers' mathematical knowledge for teaching, the Diagnostic Teacher Assessments in Mathematics and Science (DTAMS) instrument was designed to assess elementary and middle grades teachers' mathematics content knowledge and pedagogical content knowledge.

The authors found that during the hybrid course, teachers' scores on both measures increased significantly, but with a much higher increase in scores on the LMT. During the mathematics course, teachers' scores on the LMT remained stable, as did scores on the PCK portion of the DTAMS test, but scores on the content knowledge portion of the DTAMS test increased further. When looking at teachers' sub-scores for a common content area, algebra, similar trends appeared. The teachers' scores on the two assessments were highly correlated at the beginning of the professional development program, but became less correlated over time. Gains in different aspects of teachers' mathematical knowledge during the two courses seemed to be detected by the two measures. Whereas teachers' common and specialized knowledge seemed to grow during the hybrid course, only their common knowledge seemed to grow during the content course. As CopurGencturk and Lubienski point out, the particular gains teachers in this study made could have been affected by characteristics of the teachers, courses, and the professional development program. Nonetheless, this study provides novel information that will be useful to researchers and evaluators about the aspects of the teachers' mathematical knowledge measured by two widely used instruments. In addition, the article underscores theoretical distinctions that have been drawn between forms of mathematical knowledge (i.e., specialized knowledge for teaching vs. common mathematical knowledge), which seem likely to develop differently in different courses and contexts. The results also support the idea that hybrid courses, which integrate mathematics and pedagogy, may offer 
fruitful opportunities for teachers to develop mathematical knowledge for teaching. We will need further research to understand how teachers may develop different components of mathematical knowledge in different mathematics and hybrid courses, as well as in other professional development contexts.

The authors of the articles in this issue of JMTE extend our thinking about ways that particular forms of professional development may give rise to different possibilities for mathematics teachers to learn. As you read about the facilitation of non-evaluative discussions during video analysis (Coles), teachers' development of shared didactic theory in open lessons (Miyakawa and Winsløw), and measures of gains in aspects of teachers' mathematical knowledge during graduate courses (Copur-Gencturk and Lubienski), you are invited to consider the complexity of supporting and understanding teachers' learning in unique contexts and for diverse purposes. 